\title{
Editorial: Advances in Nuclear Power Engineering
}

\author{
Zhaoming Meng ${ }^{1}$, Jun Wang ${ }^{2 *}$, Kaiyi Shi ${ }^{2}$ and Shripad T. Revankar ${ }^{3}$ \\ ${ }^{1}$ College of Nuclear Science and Technology, Harbin Engineering University, Harbin, China, ${ }^{2}$ Department of Engineering Physics, \\ University of Wisconsin-Madison, Madison, WI, United States, ${ }^{3}$ Department of Nuclear Engineering, Purdue University, West \\ Lafayette, IN, United States
}

Keywords: gen IV reactor, small modular reactor, thermal hydraulic, neutronic, containment

\section{Editorial on the Research Topic}

\section{Advances in Nuclear Power Engineering}

Nuclear power has been used widely around the world and is considered a highly efficient and clean energy source (Kim and Alameri, 2020). Many organizations around the globe are leading the efforts to develop new technologies to improve the economy and safety (Openshaw 2019). The research topic "Advances in Nuclear Power Engineering" aims to publish the most advanced and timely research results. The articles include research results on Gen IV reactors, small modular reactors, reactor physics, reactor thermal hydraulics, advanced safety technologies, and related topics. Variety of important areas are covered in these topics including theoretical,

OPEN ACCESS

Edited by: Muhammad Zubair, University of Sharjah, United Arab Emirates

Reviewed by: Marco Colombo, University of Leeds, United Kingdom

*Correspondence: Jun Wang jwang564@wisc.edu

Specialty section: This article was submitted to Nuclear Energy, a section of the journal Frontiers in Energy Research

Received: 15 November 2020 Accepted: 17 December 2020 Published: 26 January 2021

Citation:

Meng Z, Wang J, Shi K and Revankar ST (2021) Editorial: Advances in Nuclear Power Engineering. Front. Energy Res. 8:629655. doi: 10.3389/fenrg.2020.629655 computational, and experimental thermal-hydraulics, multiphase heat transfer, neutronics, uncertainty analysis, aerosol transport, and scaling considerations.

Zhang et al. discuss on the Gen IV sodium-cooled fast reactor heat transfer in their article "Theoretical Investigation on the Fully Developed Turbulent Heat Transfer Characteristics of Liquid Sodium." In the article "Numerical Analysis of FLiBe Laminar Convective Heat Transfer Characteristics in Tubes Fitted with Coaxial Cross Twisted Tape Inserts," Yang et al. present computational heat transfer results on Gen IV molten salt reactor. Zhang et al. discuss design of the small modular reactors in the article "Comparisons of Reduced Moderation Small Modular Reactors with Heavy Water Coolant." Those works provide an insight view of the nextgeneration reactor design include not only high temperature Gen IV reactors but also small modular light water reactor.

Song et al. share their results of computational studies in the article "GPU Based Two-Level CMFD Accelerating Two-Dimensional MOC Neutron Transport Calculation.” The neutronic work shows the multidimensional neutronic and thermal information in the reactor core.

The results on thermal-hydraulics experimental work are given by Li et al. in the article "The Effect of Different Branch Angles and Different Branch Pipe Sizes on the Onset Law of Liquid Entrainment”; Gao et al. in the article "Influence of the Size and the Angle of Branches Connected to the Main Horizontal Pipe on the Onset of Gas Entrainment"; Mao et al. in the article "Natural Convection Heat Transfer of the Horizontal Rod-Bundle in a Semi-closed Rectangular Cavity"; Ren et al. in the article "Visualization Experiment of Bubble Coalescence in a Narrow Vertical Rectangular Channel"; and by Wang et al. in the article "Study on the Breakdown Mechanism of Water Film on Corrugated Plate Wall Under the Horizontal Shear of Airflow: A Short Communication." The experimental thermal-hydraulics work aims at the improvement of the heat transfer coefficient and reactor safety.

Other thermal-hydraulics related works include the work of Wang et al. in the article "Review and Prospect of the Measurement Technology of the Thickness of the Liquid Film on the Wall of the Corrugated Plate Dryer"; Saeed et al. in the article "Sensitivity Analysis of Some Key Factors on Turbulence Models for Hydrogen Diffusion Using HYDRAGON Code"; Zhou et al. in the article 
"Analysis of Measuring Characteristics of the Differential Pressure Water-Level Measurement System Under Depressurization Condition"; Zhou et al. in the article "Numerical Study of the Influence of Tube Arrangement on the Flow Distribution Inside the Heat Exchanger in the PCCS"; Wang et al. in the article "Numerical Study on Laminar-Turbulent Transition Flow in Rectangular Channels of a Nuclear Reactor"; Huang et al. in the article "Study on Typical Design Basis Conditions of HPR1000 With Nuclear Safety Analysis Code ATHLET"; Sun et al. in the article "An Improved Best Estimate Plus Uncertainty Method for SmallBreak Loss-of-Coolant Accident in Pressurized Water Reactor"; and Zhang et al. in the article "Uncertainty analysis on $\mathrm{k}-\varepsilon$ turbulence model in the prediction of subcooled boiling in vertical pipes." The theoretical and numerical thermalhydraulics work expands the boundary of experimental work.

Reactor containment is the final safety boundary of the nuclear power plant. Articles related to reactor containment include

\section{REFERENCES}

Kim, J. H., and Alameri, S. A. (2020). Harmonizing nuclear and renewable energy: case studies. Int. J. Energy Res. 44 (10), 8053-8061. doi:10.1002/er. 4987

Openshaw, S. (2019). Nuclear power: siting and safety. Abingdon, United Kingdom: Routledge. articles by Liu et al. "Scaling Design of the Pressure Response Experimental Facility for Pressure Suppression Containment" and Tao et al., "Experimental study on natural deposition characteristics of aerosol in the containment". Those works are important to help containment integrity during beyond design basic accident conditions.

This research topic received good response from authors and successfully attracted dozens of submissions. After the peer-review and editor's efforts, this research topic finally published nineteen articles. We want to thank all the reviewers, authors, and support from the editor office of Frontiers in Energy Research.

\section{AUTHOR CONTRIBUTIONS}

$\mathrm{ZM}$ is the leading editor; JW is the contact editor; KS and SR are senior people.

Conflict of Interest: The authors declare that the research was conducted in the absence of any commercial or financial relationships that could be construed as a potential conflict of interest.

Copyright (c) 2021 Meng, Wang, Shi and Revankar. This is an open-access article distributed under the terms of the Creative Commons Attribution License (CC BY). The use, distribution or reproduction in other forums is permitted, provided the original author(s) and the copyright owner(s) are credited and that the original publication in this journal is cited, in accordance with accepted academic practice. No use, distribution or reproduction is permitted which does not comply with these terms. 